\title{
LEARNING TO CIRCUMVENT THE LIMITATIONS OF THE WRITTEN-SELF: THE RHETORICAL BENEFITS OF POETIC FRAGMENTATION AND INTERNET "CATFISHING"
}

\author{
Meghan Punschke Nolan
}

\section{ABSTRACT}

One of the most complex relationships we have to convey as humans is the written identification of that which we call the self. Despite the fact that we are multifaceted beings, contemporary lingual limitations often force the perception of the individual as a definitive entity through three fundamental normative communication standards: authority, authenticity and moral accountability. This essay examines the resulting paradoxes of writerly identity in relation to these constructs, and simultaneously proposes that the way to rectify such issues is to embrace disparate identity performances of writings past and present.

Using research from multiple disciplines, including sociolinguistics, literary theory, and composition studies, this essay asserts that there is a great deal to be learned from the practices of two unlikely genres of written communicationSpecifically, it draws a parallel between current internet culture and poetics, as the phenomenon of "catfishing" (or creating and portraying complex fictional identities through online profiles) parallels earlier Modernist acts of fragmentation through poetry. Therefore, this paper argues that although their motives may differ considerably, both endeavours are useful rhetorical performances in that they provide a practical framework for circumventing common lingual identity traps. Ultimately, it suggests that these unconventional perspectives of the "impersonal" in and through writing can help us to (re)approach the methodology of lingual identification and those written performances of the self (professional and everyday) that may not properly serve us.

\section{KEY WORDS}

Modern Poets; Fragmentation; Catfish; Self; Poetics

\section{INTRODUCTION}

In the individual, unsupplemented languages, what is meant is never found in relative independence, as in individual words or sentences; rather, it is in a constant state of flux - until it is able to emerge as pure language from the harmony of all the various ways of meaning. - Walter Benjamin (257)

The written identification of that which we call the self is one of the most complex relationships we have to convey as humans. Interestingly, among the many aspects frequently attributed to one's person, writerly identity is rarely addressed as a factor, as it is a construct 
believed to be reserved for those who call themselves and/ or are designated by others specifically as "writers." However, the truth is that anyone who possesses the ability to write in effect demonstrates a written-self. For regardless of the type of composing one does, whether it be everyday communications like texts and emails or more formal missives, the written word plays an important role in shaping and articulating one's identity. With that said, because the act of writing is often overlooked as a performance of the self by the average person, non-academic discussions focusing on the restrictive nature of such expressions are even scarcer.

In this essay, I clarify the primary constraints of self-identification in writing of all kinds, and subsequently examine fragmentation - a rhetorical practice mastered by Modern poets, now inadvertently imitated in the virtual sphere by individuals referred to as "Catfish" - as this practice deliberately creates tension for these restrictive ideals. Poetic fragmentation offers logical context for this mode of analysis, as it is the intentional division of the self in writing in order to interrogate interrelated social conventions such as identity, language, culture, politics, and more. "Catfishing," on the other hand, or the current internet trend of creating and portraying complex fictional identities through online profiles, provides a necessary counterpoint because, although their motives may differ considerably, they are in practice identical demonstrations of the impersonal aesthetic. As Sherry Turkle has noted, "While in recent years, many psychologists, social theorists, psychoanalysts, and philosophers have argued that the self should be thought of as essentially decentered, the normal requirements of everyday life exert strong pressure on people to take responsibility for their actions and to see themselves as intentional and unitary actors" (15). And so, despite a postmodern viewpoint and internet culture that promote multitudinous performances of fragmentation, the Poet and Catfish are still oddly bound by the imbedded subconscious tenets of lingual exchange as well. Viewing these performances side-by-side not only reveals the intricacies of our slipshod association with the social parameters of lingual identity, especially when it comes to perceptions of morality, but it can also nudge even those who do not necessarily identify as writers toward a better understanding of the sheer possibilities of the written-self.

\section{THE TACIT MARgins OF THE WRITTEN-SELF}

Before we can retool conceptions of selfhood or begin to appreciate the benefits of Modern and contemporary plays of fragmentation, we must first evaluate the subconscious lingual constraints these acts of self-definition grate against. Writerly identity is consistently determined through a multifaceted process of lingual regulation in social and institutional ideals in a process sociolinguist and philosopher Pierre Bourdieu best explains as "habitus," or the production of normative standards through learned models of speech and writing. Written exchanges, as with all aspects of communication (including their verbal and gestural counterparts), are riddled with unspoken guidelines, and each discourse community, speech genre or social group we inhabit has fundamental rules that its members must follow. That is not to say that at some point each of us was formally handed a list of dos and don'ts for our interactions - although I suspect most of us did receive such imperatives throughout our schooling. But rather, as Bourdieu contends, these unstated "dispositions generate practices, perceptions and attitudes which are regular without being consciously co-ordinated [...]" (12). That is to say, each group of which we are a part (e.g. a specified professional field, discipline, school, culture, family unit, etc.), indoctrinates a set of ever-present lingual standards which are only superficially acknowledged and, author bell hooks notes, these unwritten rules are consistently treated as if they are steadfast universal values that traverse the borders of disciplines, institutions, cultures, generations and more (35). Nevertheless, individuals are expected to (and for the most part do) blindly adhere to them.

This function of the individual in relation to the tenets of habitus is a cornerstone of power dynamics and thus, writing, one of our most common forms of communication, is essentially a currency governed by three interrelated principles that underpin written conceptions of the self as well. According to my research, these ideologies are best described as: 
authority, as in the acceptance of one as member or expert in a given speech genre in relation to his $^{1}$ writing; authenticity, as a social judgment of the sincerity or veracity of a writer's statements- a collective perception of text not necessarily aligned with the writer's personal creative approach; and moral accountability, as an appraisal of whether or not those statements are acceptable according to the ethical standards of a given group. In this way, "The habitus also provides individuals with a sense of how to act and respond in the course of their daily lives" (Bourdieu 13), and because our personal worth is invariably tied to these abstruse social perceptions of what is considered culturally "valuable" or "acceptable," it also provides the basis for self-judgment and self-identification in writing and other communiqués.

The hidden principles of lingual identification are further convoluted by a common and detrimental misconception wherein the regular practice of normative communications creates the perception of concreteness. Western ideals require related identity performances to be perceived as fixed entities through "I am" statements and other indications of permanence. And, while this may feel appropriate in practice, mainly because we are taught to use and view language in this way, it is extremely misleading for several reasons. First, the obvious - no one is static - we all change from moment-to-moment at the cellular level and beyond (whether we like it or not), and this constant transformation coincides with the highly relative function of identity that Bourdieu emphasizes. Moreover, because all communications of identity are in fact variable, sociologists and philosophers alike question the ability to formally possess a singular sense of self, hence Judith Butler's quip: "The 'I' has no story of its own- it's a story of relation" (8), and as writers we often unintentionally perform additional multitudinous acts of identity through our writing practices.

Most adult writers and many adolescents regularly exhibit simultaneous personalities through their rhetorical choices. For example, one's professional communications will distinctly differ in tone, content, and terminology from those with friends. The extent to which the majority of us display this fluidity of self through writing is undeniably tied to the very discourse communities of which we are members as well, as every one of them has very different measures for these ideals that additionally complicate the delivery and perception of self. Some of us are more dynamic in our lingual performances of identity than others, and so the caveat is that people who are a part of fewer social groups and/ or inhabit multiple communities with less of an expectation for varying performances of identity may not present fluctuating acts of the written-self as habitually or smoothly. I am reminded of Roz Ivaničs study in Writing and Identity (1998), in-where students from low-income neighborhoods exhibit limited adaptability in this skill (sometimes referred to as "code switching"). But, for those who do enact these varying façades of self regularly, they consciously and subconsciously recognize that their decisions produce a desired effect, such as acceptance among colleagues. Strangely, they frequently do so without interrogating the numerous roles they actually enact and fulfill through these common communications.

Another self-related concern emerges in relation to our lingual attachments. Westerners particularly are trained to see words as a kind of personal property, almost as if they form a resonating appendage rather than actual demonstrations of selfhood. This is evident in recent changes in intellectual property rights (IPRs) and copyright laws, because as economists Fagerberg et al. state, "despite their long history, until recently IPRs did not occupy a central place in debates over economic policy, national competitiveness, or social welfare" (266). However, this notion of words as property is directly countered in the research of sociolinguist Erving Goffman:

[T] here is the obvious but insufficiently appreciated fact that words we speak are often not our own, at least our current "own." [...] But although who speaks is situationally circumscribed, in whose name words are spoken is certainly not. Uttered words have utterers; utterances, however, have subjects (implied or explicit), and although these may designate the utterer, there is nothing in 
the syntax of utterances to require this coincidence. We can as handily quote another (directly or indirectly) as we can say something in our own name. This embedding capacity is part of something more general: our linguistic ability to speak of events at any remove in time and space from the situated present.) (Forms of Talk 3)

Goffman contends that since we each have little-to-no rightful ownership of the words we so frequently use, there exists an even larger issue of identification through languagealthough we often assume that the person saying the words in a sense possesses them, there is no syntactical rule that requires this to actually be so. By extension, a name, one of the preeminent requirements of identification for humans, is not definitively attached to an utterance in a given instant, nor is a name (or person) truly affixed to the product of writing as it cannot/ does not live within a singular moment of transcription. Moreover, through the generative principles of habitus we are almost expected to regularly employ the expressions of others as if they are our own, and it is how we approach this exact endeavor that ultimately decides our relation to a community as either member or outcast. And so, not only do we exceed the relative boundaries of space and time through such appropriations in everyday expressions, but there too exists an integral transcendence of the borders of identity through constant lingual emulation. And, as a result of the customary "ritualization" of language and its associated body language or gestures, we often perform these acts without acknowledgment of the underlying restrictions.

Unfortunately, these masterfully nuanced theatrics of lingual identity for the most part go unnoticed, as the normative structures force us into a perpetual paradox: Individuals must adhere to the desired perception of a self that is a stable entity expressed and defined through presumptions of the "concrete," despite the fact that identity, through its varied performances, is undeniably fluid in lingual expression. And, while the average person may not be fully aware of his own (re)inscribed contrivances, lingual emulation is a technique that both the Modern poet and the internet Catfish (as representations of formal and informal genres of writing respectively) often intentionally employ with the skewing of these identification values firmly in mind.

\section{Social Perceptions of the Fragmented Self in Writing}

Humans have an insatiable need to identify themselves linguistically (and otherwise) through commonalities. Thus, renowned French theorist, Michele Foucault notes that up until the end of the sixteenth century, "it was resemblance that organized the play of symbols, made possible the knowledge of things visible and invisible, and controlled the art of representing them" (17). That is to say, identifying things via similarities - the very heart of that which we call poetic language - was indeed once the conventional mode of lingual communications. And so, for centuries, the Poet was hailed as the master of the written word, mostly because of his ability to deftly employ the initial intents at the root of the convention, until a fundamental shift in language usage of the seventeenth century drastically changed the landscape of lingual designation as a whole. Things began to be classified as they are today, for the most part according to their perceived differences.

As with language, the Poet's esteemed role transformed over time. And, because the Poet's techniques are now viewed as separate from the everyday agendas of written communications, he is no longer positioned as lingual virtuoso to the masses. Subsequently, Foucault states that it is only the Poet and his antithesis, the "madman," who even dare to intentionally use the original lingual systems of resemblance (or similitude) in order to make connections through written language. And, for that, they must face a curious consequence:

The poet brings similitude to the signs that speak it, whereas the madman loads all signs with a resemblance that ultimately erases them. They share, then, on the outer edge of our culture and at the point nearest to its essential divisions, 
that 'frontier' situation - a marginal position and a profoundly archaic silhouette - where their words unceasingly renew the power of their strangeness and the strength of their contestation. Between them there has opened up a field of knowledge in which, because of an essential rupture in the Western world, what has become important is no longer resemblances but identities and differences. (50)

Therefore, Foucault asserts that in the shift toward the current classification model of languages and away from poetic conventions, the Poet and his writerly antithesis are positioned at the outermost poles of what is considered normative language usage through their continued, intentional use of similitude - an ideal Foucault further delineates as the written processes of convenientia or those resemblances made via convenience or vicinity; aemulatio which enables us to emulate one another regardless of time or proximity, the very technique that Goffman attests everyone unintentionally applies through social protocols, although most often verbally; analogy or metaphorical comparisons through which unlikely things gain contextual similarity, perhaps the most recognized and understood form of similitude as it is commonly practiced outside of poetics; and, sympathy through which the individuality of things seems to disappear within displays of overwhelming and assumed likenesses (17 - 24). The Poet is considered an outsider because his repeated application of all of these methods complicates common ideas to such a degree that he must regularly rectify the tangible with that which is decidedly not in order for his ideas to be communicable at all.

Poets too are obligated to perform within the parameters of authority, authenticity, and moral accountability. Yet, the Poet, having extensive knowledge in both forms of communication - the antiquated procedures of similitude, as well as the everyday practices of disparity - has a propensity to evaluate the complexities of such lingual identifications for himself and others. And, this ability is only enhanced according to T.S. Eliot, because "the poet has, not a 'personality' to express, but a particular medium, which is only a medium and not a personality, in which impressions and experiences combine in peculiar and unexpected ways" (118). Thus, many poets have addressed this conception of the self, although with slightly different ambitions. Early on the Humanists used imitatio as a way to break away from medieval perceptions of the fixed-self, and later the Romantics explored written identification through the liminal often intertwining autobiography and mysticism in order to interrogate the relationship of man with the natural and spiritual worlds. It was the Modernists, however, who advanced this detailed inquiry of writerly identity, as they mastered the process of poetic fragmentation, or what Maud Ellmann refers to as the poetics of "impersonality," through their extensive depersonalization of the self $(4-7)$.

Fragmentation as a rhetorical performance of identity entails an author intentionally writing under alternate personas and/ or altering the normal expectations of identity related discourse, and this has long been thought of as an inherent skill for the Poet for several reasons. Primarily, the purpose of poetic language via the function of the four similitudes is precisely to blur the barriers of identities through resemblances, but also there is a common belief that the Poet operates on divine inspiration. So, in essence, many accede to the idea that "Poetry writes itself- and the poet is a mere amanuensis [...]" - a meagre recorder, or a sort of hollow vessel through which the divine is expressed- and "the writer [therefore] has the power to decide to overcome himself" whenever he chooses (M. Ellmann 4). Through this writing process, the Poet, unlike any other, is said to possess a "double soul" through which he is able to inhabit varying ways of being simultaneously. The resulting personas, most often either distortions of existing identities or fictional exaggerations of one's own characteristics, are often described as writerly alter egos or "masks." It is worth noting, however, that the latter is a misnomer predicated on the aforementioned belief in a primary self, thus coined to make obvious the obscuring of that immovable locus. Through their various written personas though, the Modernists use the social requirements of language in order to express a more accurate representation of the multitudinous qualities of written identity. 
The Modernist poets who best tackled lingual constraints in relation to the individual through fragmentation were Fernando Pessoa, T.S. Eliot, Ezra Pound and W.B. Yeats. Each of these poets consciously embodied elements of the impersonal in his own way: Pessoa through his extensive heteronymia ${ }^{2}$, Eliot in his divisions of self in The Waste Land (1922) and Four Quartets (1943), Pound through his description of "Vorticism" (1914) (a concept similar to Keats's Negative Capability which addresses the Poet's written ability to step "outside of himself") and relentless appropriation in The Cantos (1922 onward), and Yeats in his personal diffusion through personae like Sherman, Howard, Robartes, and Aherne. And, as scholar Robert Crawford suggests, these Modern poets do this through a combination of the splintering of language itself, as in The Waste Land or The Cantos which both use a smattering of dialects throughout, as well as identity in order to consciously problematize our notions of "native language" and the unified self (64). Remarkably, this incredibly high-brow endeavor has found a new purpose on the internet, as Catfish use the same techniques, but for very different reasons.

In her book, Life on Screen (1995), Sherry Turkle discusses how individuals currently construct identity through, and as a result of, interactions in cyberspace. Specifically, she suggests that ever-changing platforms and abundance of computer-related communications, particularly those with artificial intelligence (AI) components, are challenging our imbedded lingual conceptions of a centralized self, because in virtual spheres individuals tend to think of themselves as multitudinous:

In the story of constructing identity in the culture of simulation, experiences on the internet figure prominently, but these experiences can only be understood as a part of a larger cultural context. That context is the story of the eroding boundaries between the real and virtual, the animate and inanimate, the unitary and multiple self, which is occurring in advanced scientific fields of research and in the patterns of everyday life. [...] But it is on the internet that our confrontations with technology as it collides with our sense of human identity are fresh, even raw. In the real-time communities of cyberspace, we are dwellers on the threshold of the real and virtual, unsure of our footing, reinventing ourselves as we go along. (10)

Turkle states that in light of current internet culture, we are moving away from an investment in a centralized Freudian conception of the self (although she is also careful to note that Freud himself did not necessarily mean for the "ego" to be used as it often is, as the representation of a concrete entity), and toward the Lacanian idea of the individual as "a realm of discourse rather than as a real thing or a permanent structure of the mind" (178) - a change that Catfish take full advantage of because their performances of fragmentation are published via the internet as opposed to in print.

Catfish, much like the Modernists, are individuals who write under alternate personas and who also, often times, adjust their written dialects accordingly. Yet, these written performances differ greatly from previously printed portrayals of the self. Catfish operate online where identities are now commonly crafted by most people through a plethora of social media sites. These sites are designed with editable profiles that make it easy to tailor personas for specific audiences most often instantaneously. Following the 2010 documentary, Catfish, the act of "catfishing" became specifically synonymous with having relationships with others online under false pretenses, as the subject of the film, Nev Schulman, discovers that the person he has long considered to be his internet girlfriend is, in fact, an already married middle-aged mother (Peterson 2013). This documentary brought attention to the widespread reality of such ploys, which have since been popularized by Schulman's follow-up MTV show of the same name inwhere individuals posing as others on the internet are regularly exposed and confronted by their victims. But, perhaps the most notable Catfish disclosure of this kind was in 2012 when Notre Dame Linebacker Manti Te'o publicly announced that his online love interest, Lennay Kekua, had died of Leukemia only to find out that she never actually existed. Instead, he was 
told that he had been chatting with a male acquaintance, Ronaiah Tuiasosopo for over a year ("Tuiasosopo Says" 2013). In all of these instances, the farce is only possible because both the Catfish and their victims are participating in online forums, in essence, working toward a common goal - to ultimately meet a partner, for purposes emotional, sexual or otherwise.

In the three-part study, "What to Tell About Me? Self-Presentation in Online Communities" (2012), Eva Schwämmlein and Katrin Wodzicki differentiate between the communication platforms often used for these types of online interactions as either "commonbond" through which people gather based on interpersonal attraction as in they communicate in order to get to know and like one another, or "common-identity" groups through which social identifications are the primary focus and the attractiveness of the group as a whole is important (388). Because of the nature of catfishing, most of the subjects on the MTV series are involved in the aforementioned common-bond groups online, and Schwämmlein and Wodzicki's studies revealed that "Through individualizing self-presentation [on common-bond sites] people do exactly what is helpful to make acquaintances" (401), frequently picking and choosing those elements which present themselves in the most favorable light. In so doing, they are not only establishing themselves as members according to the unspoken tenets of that discourse community, but they are also enacting a contemporary version of one of two forms of similitude, aemulatio and/ or sympathy, depending on how far they take their written performances.

Unfortunately, because both parties are willfully participating in the common-bond group, it can almost appear as if the victim is complicit in the deceit or has a willingness believe their online suitor's presentation despite the fact that they too "fudge" things at times. However, their gullibility may be the result of a strong desire to adhere to previously established cultural cues-the very cues that Catfish often use to attract their victims in the first place. In his paper, "Interpreting Instant Messaging: Context and Meaning in Computer-Mediated Communication" (2007), David Jacobson reports on his anthropological study of how people contextualize behaviors through computer-mediated communications (CMCs) such as the instant messaging (IM) systems Catfish use, and he states that these "dyadic relationships (and their relational cultures) are differentiated by the kind of knowledge each party holds on one another" (362). In other words, even with our current attachment to or dependence on technologically-based communications, most of the context applied to our understanding of online discourse exchanges is, in fact, derived from prior social contact with the person outside of online communications. Therefore, in an online-only relationship through a common-bond platform, it is much easier for people to not only misinterpret meaning, but also for them to miss social warning signs altogether.

With that said, as strange and infuriating as these online "hoaxes" may seem, the Catfish's rhetorical practice itself essentially mimics that of the Modern poet. For instance, Catfish, too, use personal experience and the desire to connect with others through it as the basis for the creation of their personas, and so the profiles they build "often contain the experiences, friends, resumes and job titles that they wish were their own" (Peterson 2013). Truthfully, this could also be said of numerous poetic personas adopted by both Pessoa and Yeats. But, unlike the Modern poet who did this as a means for revealing truths about ourselves and the world in which we live, the Catfish does it to deceive and because he presumably thrives on taking control of the way others see him. There remains a significant difference in the intent - the very concept in which the restrictive terms of communication are so often rootedand, when examining these performances in light of such expectations, catfishing appears to be more like Modernist fragmentation's thoroughly embarrassing cousin than its identical twin.

While Turkle claims that our postmodern way of thinking readily accepts multitudinous identity performances as standard (180), that is not necessarily true, as we still have drastically different perceptions of these two very similar performances. Because of their dissimilar motives, the Poet, undeniably an outcast from normative discourse communities, is held in relatively high esteem, whereas the Catfish is thought of as a pariah for his interpretation of the 
impersonal in CMCs. The reason for this dichotomous reaction is two-fold. Firstly, as author and literary critic Lionel Trilling notes, "We are habituated to the idea that society, though necessary for survival, corrupts the life it fosters, and most of us give this idea some degree of assent. But we receive with no such tolerance the idea that literature is an accomplice in the social betrayal" $(60-61)$. This betrayal Trilling refers to has dual meaning in that we will not tolerate literature that intentionally seeks to mislead us, but we also will not abide literature that does not fulfill its main purpose in terms of genuine experiential connectivity. The latter is a different kind of deceit founded in our expectation that literature is an art form meant to express truths. The Poet, who fulfills these needs stands for something "greater" than the Catfish simply because his writing is art-his fragmentation is perceived as a technique not intended to deceive, but rather to illuminate. So, as removed as it may be from the norm, poetic fragmentation does not betray us because it realizes its artistic objective. Poesy is still primarily regarded as a means of entertainment, "[...] and the pleasure resulting from the manner in which they [poets] express the influence of society or nature upon their own minds, communicates itself to others, and gathers a sort of reduplication from that community" (Shelley par. 3). And, while catfishing may also bring people together through the written word, the same credence cannot be given to its product principally because it originates with the selfish intent to swindle. Its entertainment value has an expiration as a decidedly short-lived amusement for all concerned.

Thus, the problem with catfishing is not found in the rhetorical practice itself, but rather that it is situated at the wrong end of the moral compass. The Catfish is perceived as having no sense of moral duty in his actions, as if he intentionally seeks to sidestep his ethical responsibilities as community member, and it is this personal awareness of his own corruption through writing that we find so deplorable. Morality as a social concept requires us to adhere to our stations in all factions of existence including our written identity performances, and it does not tolerate those who dissent. The Catfish's fraudulent character, then, is analogous to a commonly loathed fictional archetype, the antihero or "villain": "The villain of plays [verse] and novels is characteristically a person who seeks to rise above the station to which he was born. He is not what he is: this can be said of him both because by his intention he denies and violates his social identity and because he can achieve his unnatural purpose only by covert acts, by guile" (Trilling 16). Trilling explains that the hallmark of any villain is a blatant contradiction and corruption of his own social identity through surreptitious acts. In this sense, the Catfish is a real-life villain - and I mean this as non-sarcastically as possible. Today's usage of the word too often conjures images of a cartoonish fiend laughing maniacally to himself as he methodically plots to dupe others. And, some clearly toe this line, like Adam, a compulsive gambler who rigs jackpots for a living and blatantly proclaims himself to be an all-around bad guy and "King of the Catfish" who has deceived upwards of 40 people with his online antics for the "fun" of it (Schulman 2014). However, most Catfish are villains in the Victorian vein, as they exhibit characteristics which are deliberately not "true to life." Much like Fagin in Dickens's Oliver Twist (1838) who presents himself regularly as the one in control through his abusive command of his band of child pickpockets, but is himself cowardly and afraid of his criminal associate Bill Sikes, Catfish, too, choose to stretch the truth for personal control or advancement. In Hegelian terms, honest aim requires that the self needs to submit to traditional ethics. And, in this regard, a lack of intent is always better than mal intent, for in everyday communications one may not always consciously intend to abide by the lingual rules (as previously noted by Goffman and Bourdieu's independent theories), but he equally possess no will to perform to the contrary and therefore means no harm to the community and/ or its other members. The Catfish, who regularly deceives in order to exceed his expected place in society and successively injures others with these actions, is thus outwardly spurned for his writerly identity.

The second reason for the contradiction in the perception of these very similar acts of fragmentation is that the Poet's authenticity is not and never would be questioned in the same manner as that of the Catfish, because the Poet's self-division is intertwined with a long tradition of moral fortitude of which I will endeavor to explain. As far back as the sixteenth 
century, we find in the work of English poet, Sir Phillip Sidney, documented evidence of the Poet weighing in on the pure moral righteousness of that role he must fulfill. (Righteous because the word poet literally means "prophet" or "seer" in Latin, and "maker" or "creator" in Greek.) And, in The Defense of Poesy Otherwise Known as an Apology for Poetry (1579) Sidney proclaims that the Poet's purpose is to affirm ethical edicts through his works, and more importantly, it is the way in which the Poet does this (through his verse) that makes him unique:

Now for the poet, he nothing affirmeth, and therefore never lieth. For, as I take it, to lie is to affirm that to be true which is false; so as the other artists, and especially the historian, affirming many things, can, in the cloudy knowledge of mankind, hardly escape from many lies. But the poet, as I said before, never affirmeth. (35)

According to Sidney, the Poet is a moral pinnacle who does not lie because he has no need to; the Poet merely reports that which is true and does not pretend that a fictionalization is anything more than a product of the imagination. Sidney also suggests that poetry itself (and therefore the Poet) holds the purest intentions of humans, because through his relationship with the divine it/ he acts as an ethical mirror. This sentiment, of Poet as moral figurehead, is echoed repeatedly throughout the years by other poets as well, such as [Percy Bysshe] Shelley, Emerson, Eliot, and Pound to name a few. In the rough notes of one of Yeats's lectures, for example, he describes the Poet's function as that of pure authenticity: "A poet is by the very nature of things a man who lives with entire sincerity, or rather, the better his poetry the more sincere his life" (qtd. In R. Ellmann 5). In Yeats's estimation, the Poet is the most genuine of all writers in terms of individual intent, as his writing exists with an effortless integrity. This does not mean that the Poet is incapable of dishonesty. It is quite the opposite, as many poets have happily staked their claims in the production of intentional artifice with their works. Their legitimacy, however, is not called into question because under the guise of art, as Sidney indicates, this brand of falsification or insincerity is done so candidly. Part of morality is also an assumed honesty of the actual words that the writer produces, and while the Poet is seen as either an over-reliable narrator of all that is and/or an artistic mastermind, the same cannot be said of the Catfish.

The "rhetoric of authenticity," according to Donna LeCourt, occurs at the axis of an allegiance to institutional standards and grander collective morals (23). But, that authenticity is hard to come by in a system that seems to devalue individualism at every turn. Catfish are automatically vilified regardless of how heart-breaking their personal tales may be. Many of them were themselves victims at some point and so they are keenly using the fragmented personas as a way to circumvent those portions of the self that they have been told (or shown) are unacceptable by society. Most of the publicly-exposed tricksters have admitted that they find safety in the written performance of self, as it captures aspects of personality that they believe they cannot express in other ways, and so they rely on the perceived anonymity of the virtual sphere. As communications expert, Joshua Meyrowitz explains, electronic media sever the traditional links between physical location and social situations and "blur the dividing line between private and public behaviors" (71), thus allowing people to "escape" from various aspects of their corporeal identifications (57). Examples of this reach far and wide among the Catfish, from Tuiasosopo who was molested as a child and condemned his homosexuality in public as something to be "recovered from" but was able to carry on an intimate relationship with Te'o as a female persona online (McGraw 2013), to Matt who, for ten years, never fabricates a single aspect of his life in his written correspondence with girlfriend Kim, but rejects her repeated attempts at in-person contact because he is afraid that his severe obesity will scare her (Schulman 2012). So, while the majority of Catfish seem to pretend to be something online that they are decidedly not by social standards, there may be an element of truth to their written performances. They are, after all, people enacting feeling through the written word, and those words and emotional displays originate with them regardless of their invented personage. And, when we consider that we all perform written identity variably, 
especially through our cyber performances of self, perhaps Trilling was correct when he stated in his 1971 in his Harvard lectures on Sincerity and Authenticity (1971) that "The truth of the self, at a certain stage of its historical development, consists in its being not true to itself, in there being no self to be true to: the truth for self, for Spirit, consists precisely in deceit and shamelessness" (44). So, regardless of motive, the Catfish is closer to the genuine article than suspected, and the artifice is really found in those written performances that maintain a false sense of constancy.

\section{CONCLUSION}

Writing is more than a means of communication; it is one of the most important methods we use for conveying personal and social perceptions of the self, and concurrently constructs identity through a fluctuating performativity. Theresa M. Lillis declares that, "'Actively creating' involves becoming aware of our tacit habits of meaning and making choices about the ways in which we wish to mean. In this process, meaning making is not just about making texts, but also about the making of our selves, in a process of becoming" (48). And so, writerly intent extends far beyond the bounds of crafting physical texts for community buy-in purposes, because through the ever-present social tenets that govern the acceptability of language usage, our written performances are predominantly a process of becoming the self. Thankfully, writing also doubles as a valuable tool that can help us to become more aware of these varying rhetorical choices, practices and roles through a reflexivity that, according to Pound, is inborn, and thus should be experienced regularly, because the very act of writing transfigures identity (M. Ellmann 139). It is important, then, to stress the writerly-self is a major component of personal identification and deserves more attention in non-academic venues.

As Turkle intimates, it is not that we have more personas now than in centuries past, but rather that online communications allow us to cycle through them more rapidly, as prior to computer-mediated communication, consistent life-long involvement with family and friends directly kept our switching of personas or "masks" under control (179). Impersonalized writing, like fragmentation, demonstrates the possibilities of the flexible self, of which we have become more comfortable with in virtual spheres, in all of our writing. It forces the writer to consciously contemplate the various writerly identities he frequently designs and inhabits. And so, perhaps this is a practice we could all benefit from, as Crawford suggests:

[I]n our postmodern weather the fragment may be the condition of speech, signaling from the English language access to a wider linguistic spectrum. Following Bakhtin and other theorists we may be happier to accept that one's "own language is never a single language"; to write in such a way that this is either implicit or explicit may be a good thing. ${ }^{3}$ (68)

Crawford indicates that contemporary fragmentation serves a greater purpose than its original inclinations artistic and cunning, as it provides a way to shift the understanding of our language usage from the singular and "concrete" toward a more accurate representation of multiplicity and fluidity. And, in turn, this intentional division of the written-self can help us to (re)approach a methodology of lingual identification that may not properly serve us, and even possibly redefine "individuality" as a construct.

However, as the Modern poet and the Catfish demonstrate, this practice must be carefully approached. Despite his position outside of the norm, the Poet is socially accepted (and even revered by some discourse communities) because his written identity performances unexpectedly manage to adhere to lingual limitations while simultaneously testing and reshaping their thresholds, and the Poet, particularly the Modernist poet, seems to operate best within this liminal space between. But, the Catfish lacks influence and legitimacy because through his similar, but calculatedly covert, interpretation of the fragmented self, he blatantly disregards the social protocols, conscious and subconscious, of lingual identity. And so, in order for this type of fragmentation to be a successful and/ or practical exercise, the writer's intent 
must always be to explore and display sincere, and more importantly, moral evaluations of the self.

\section{END NOTES}

1. For ease, I have chosen to address the writer, the Poet and the Catfish all in the masculine. There is no intended connotation for this choice.

2. Portuguese poet, Fernando Pessoa wrote under 81 different personae referred to as "heteronyms." Each heteronym has its own writing style, background, profession, etc. thus making Pessoa one of the strongest examples of this type of Modernist fragmentation in action.

3. Crawford is sub-referencing a selection from M. M. Bakhtin's The Dialogic Imagination (1981). p. 66. Full details for this text can be found in the Works Cited.

\section{WORKS CITED}

Bakhtin, Michail Michajlovič, and Michael Holquist. The Dialogic Imagination: Four Essays. Austin: U. of Texas P, 2011. Print.

Benjamin, Walter. Walter Benjamin: Selected Writings, Volume 1: 1913-1926. Ed. Marcus Bullock and Michael W. Jennings. Cambridge: Belknap, 2004. Print.

Bourdieu, Pierre, and John B Thompson. Language and Symbolic Power. Cambridge: Harvard UP, 1991. Print.

Butler, Judith. Giving an Account of Oneself. New York: Fordham UP, 2005. Print.

Catfish. Dir. Henry Joost and Ariel Schulman. Perf. Nev Schulman, Henry Joost, Ariel Schulman, Stephen Fogarty. Relativity Media/ Rogue Pictures, 2010. Film.

Crawford, Robert. The Modern Poet: Poetry, Academia, and Knowledge since the 1750s. Oxford: Oxford UP, 2004. Print.

Dickens, Charles, and Philip Horne. Oliver Twist. Reissue edition. London ; New York: Penguin Classics, 2003. Print.

Eliot, T. S. The Waste Land. Ed. Michael North. 1st edition. New York: W. W. Norton, 2000. Print.

Ellmann, Maud. The Poetics of Impersonality: T. S. Eliot and Ezra Pound. New edition. Cambridge: Harvard UP, 1988. Print.

Ellmann, Richard. Yeats: The Man and the Masks. First Edition. New York: W. W. Norton, 2013. Print.

Fagerberg, Jan, David C. Mowery, and Richard R. Nelson. The Oxford Handbook of Innovation. Oxford Handbooks Online, 2006. Web. 21 Mar. 2015.

Foucault, Michel. The Order of Things: An Archaeology of the Human Sciences. New York: Vintage, 1994. Print.

Goffman, Erving. Forms of Talk. Philadelphia: Uof Pennsylvania P, 1981. Print.

---. The Presentation of Self in Everyday Life. New York: Doubleday, 1990. Print.

hooks, bell. Teaching to Transgress: Education as the Practice of Freedom. New York: Routledge, 1994. Print.

Ivanič, Roz. Writing and Identity the Discoursal Construction of Identity in Academic Writing. Amsterdam; Philadelphia, PA: John Benjamins, 1998. Open WorldCat. Web. 3 Oct. 2013.

Jacobson, David. "Interpreting Instant Messaging: Context and Meaning in Computer-Mediated Communication." Journal of Anthropological Research 63.3 (2007): 359-381. Print.

LeCourt, Donna. Identity Matters: Schooling the Student Body in Academic Discourse. Albany: State U of New York P, 2004. Print. 
Lillis, Theresa M. Student Writing: Access, Regulation, Desire. Routledge, 2002. Print.

McGraw, Phil, prod. "Exclusive: The Man behind the Manti Te'o Girlfriend Hoax." Dr. Phil Show. CBS. Hollywood, CA, 31 Jan. 2013. Web. 27 Dec. 2014.

Meyrowitz, Joshua. No Sense of Place: The Impact of Electronic Media on Social Behavior. Oxford UP, 1985. Print.

Peterson, Hayley. "'Catfishing': The Phenomenon of Internet Scammers Who Fabricate Online Identities and Entire Social Circles to Trick People into Romantic Relationships." MailOnline. Associated Newspapers Ltd. London, U.K. 17 Jan. 2013. Web. 6 Dec. 2014.

Schulman, Nev, and Max Joseph, dirs. "John \& Kelsey." Catfish: The TV Show. MTV. Viacom, New York, NY, 31 Aug. 2014. Television. Transcript. Web. 22 Jan. 2015.

Schulman, Nev, and Max Joseph, dirs. "Kim \& Matt." Catfish: The TV Show. MTV. Viacom, New York, NY, 26 Nov. 2012. Television. Web. 26 Jan. 2015.

Schwämmlein, Eva, and Katrin Wodzicki. "What to Tell About Me? Self-Presentation in Online Communities." Journal of Computer-Mediated Communication 17.4 (2012): 387-407. Wiley Online Library. Web. 24 Mar. 2015.

Shelley, Percy Bysshe. A Defense of Poetry. English Essays: Sydney to Macaulay. Harvard UP. Print. The Harvard Classics 1909-14.

Sidney, Sir Philip, and Albert Stanburrough Cook. The Defense of Poesy: Otherwise Known as An Apology for Poetry. Boston: Ginn, 1890. Print.

Trilling, Lionel. Sincerity and Authenticity. Cambridge: Harvard UP, 1972. Print.

“Tuiasosopo Says He Was in Love with Te'o." ESPN.com. 31 Jan. 2013. Web. 26 Jan. 2015.

Turkle, Sherry. Life on the Screen. Edition 2011. Simon and Schuster, 1995. Print.

Meghan Punschke Nolan is a professor of composition and literature at St. John's University and Westchester Community College. She has an MA in English, an MFA in Creative Writing - Poetry, and is currently a doctoral candidate A.B.D. at St. John's University. 